\title{
PROFESSOR NA PEDAGOGIA HOSPITALAR: ATUAÇÃO E DESAFIOS
}

\author{
Damaris Caroline Quevedo de Melo, Vanda Moreira Machado Lima
}

Universidade Estadual Paulista - FCT/UNESP, Curso de Pedagogia, Departamento de Educação, Presidente Prudente, SP. e-mail: damaris_melo92@hotmail.com. Financiamento: FAPESP.

\section{RESUMO}

O professor é um elemento fundamental na busca de qualidade do ensino, mas um profissional com formação qualificada e que compreenda criticamente seu papel no contexto educacional brasileiro, essencialmente na Pedagogia Hospitalar. Este texto visa refletir sobre o papel e desafios do professor para desenvolver uma ação docente qualificada na pedagogia hospitalar, principalmente na educação formal em classes hospitalares. A pesquisa se insere na abordagem qualitativa, utilizando a pesquisa bibliográfica e pesquisa documental em sites do MEC e Secretaria de Educação do Estado de São Paulo. Verificamos que nas DCNs da Pedagogia (BRASIL, 2006) o curso formaria o pedagogo para atuação em espaços escolares e não escolares, entretanto prioriza a formação de professores para o espaço escolar, desconsiderando uma área da docência de extrema relevância que é a classe hospitalar. Constatamos alguns desafios da docência na Pedagogia hospitalar: direito negado, desvalorização da Pedagogia Hospitalar; relação com sofrimento e morte; relação pedagogo e família; ausência da estrutura física e de profissionais qualificados.

Palavras-chave: Formação de Professor, Curso de Pedagogia, Pedagogia Hospitalar, Classe Hospitalar, Desafios da Docência.

\section{TEACHER PEDAGOGY IN HOSPITAL: PRACTICE AND CHALLENGES}

\begin{abstract}
The teacher is a key element in the quest for quality education, but with a professional qualified and critically understand their role in the Brazilian educational context, essentially the Hospital Pedagogy training. This text aims to reflect on the role and challenges of the teacher to develop a qualified teacher in action teaching hospital, especially in formal education in hospital schools. The research fits into a qualitative approach, using literature and documentary research in the MEC sites and Education Department of the State of São Paulo. We found that the DCNs of Pedagogy (BRAZIL, 2006) the course form the teacher to work in school and not school, however prioritizes the training of teachers for the school environment, disregarding an area of teaching is extremely important that the hospital class. We note some challenges of teaching hospital in Pedagogy: right denied, devaluation of Hospital Pedagogy; relationship to suffering and death; pedagogue and family relationship; lack of physical infrastructure and skilled professionals.

Keywords: Teacher Training, Pedagogy Course, Hospital Pedagogy, Hospital Class, Challenges of Teaching.
\end{abstract}




\section{INTRODUÇÃO}

A educação é um direito garantido pela legislação brasileira a toda criança, inclusive a criança hospitalizada? Essa questão originou esta pesquisa de iniciação científica financiada pela FAPESP, que visa investigar a formação de professores para atuar na Pedagogia Hospitalar, enfatizando seu papel relevante na formação integral dos estudantes hospitalizados. Mas este texto visa refletir sobre o papel e desafios do professor para desenvolver uma ação docente qualificada na pedagogia hospitalar, principalmente na educação formal, em classes hospitalares.

Diante desse objetivo é relevante apontar que a expressão "educação" envolve um conceito amplo. Na Lei de Diretrizes e Bases da Educação Nacional n. 9394/96 (BRASIL, 1996) no artigo 10 esse conceito "abrange os processos formativos que se desenvolvem na vida familiar, na convivência humana, no trabalho, nas instituições de ensino e pesquisa, nos movimentos sociais e organizações da sociedade civil e nas manifestações culturais". Com essa compreensão a expressão educação envolve três aspectos: a Educação Informal carregada de valores e culturas próprias de pertencimento e sentimentos herdados, a Educação não formal baseada na construção da sociedade com princípios de igualdade e justiça social fortalecendo o exercício da cidadania, e a Educação formal desenvolvida em escolas e instituições organizadas por lei, são ambientes normatizados com regras e padrões, tem objetivos pré- estabelecidos relativos ao ensino e aprendizagem.

A escola é a instituição responsável pelo desenvolvimento da educação formal, cuja função envolve três aspectos na visão de Aquino (2000): epistêmica do ensino que visa proporcionar aos alunos a construção do conhecimento mediante $\mathrm{o}$ trabalho do professor; a dimensão socializante, preparação do aluno cidadão para o convívio em grupo e na sociedade e por último, a dimensão profissionalizante que assegura a qualificação do aluno para o mundo do trabalho. Esta função social da escola exige uma prática educativa, que "envolve a presença de sujeitos que ensinam e aprendem ao mesmo tempo, de conteúdos (objetos de conhecimento a ser aprendido), de objetivos, de métodos e de técnicas coerentes com os objetivos desejados" (LIBÂNEO; OLIVEIRA; TOSCHI, 2003, p. 168).

Entretanto, há casos em que determinados alunos por motivos de doença não podem ir à escola, porém a educação especial enquanto modalidade de ensino deverá oferecer um atendimento educacional especializado podendo ser oferecido em classes hospitalares como previsto pelas Diretrizes Nacionais para Educação Especial Básica (DNEEB). A 
educação hospitalar é um direito garantido pela legislação brasileira a toda criança em situação de internação, porém, nem todas fazem uso do mesmo (CONCEIÇÃO, 2008).

\section{METODOLOGIA}

Considerando nossos objetivos esta pesquisa é de abordagem qualitativa e como instrumentos de coleta de dados apresentados neste texto utilizamos a pesquisa bibliográfica e pesquisa documental em sites do MEC e Secretaria de Educação do Estado de São Paulo. Desse modo a pesquisa não foi apresentada ao Comitê de Ética em Pesquisa (CEP) por não envolver, nesta fase, seres humanos.

\section{RESULTADOS}

Os resultados evidenciam três aspectos discutidos a seguir: 1. Legislação Nacional que estabelece o curso de Licenciatura em Pedagogia que forma pedagogos para atuarem no espaço escolar e não escolar. 2. Contextualização da Pedagogia hospitalar, como um tema relevante, atual e necessário na formação de professores que atuarão em classes hospitalares. 3. Papel e desafios do professor para atuar na educação formal em espaço não escolar, ou seja, na classe hospitalar.

\section{DISCUSSÃO}

\section{CURSO DE PEDAGOGIA: ESPAÇO DE FORMAÇÃO PARA PEDAGOGIA HOSPITALAR?}

O curso de Pedagogia no Brasil surge em 1939, mas vem sendo investigado e pesquisado no âmbito acadêmico, bem como sendo alvo de atenção das políticas públicas de formação de professores. Atualmente o curso de Pedagogia está regulamentado pelas Diretrizes Curriculares Nacionais (BRASIL, 2006) na qual o curso visa formação do pedagogo para o espaço escolar e não escolar, no entanto prioriza a docência como elemento chave, conforme trecho abaixo.

Art. 4ㅇ $\mathrm{O}$ curso de Licenciatura em Pedagogia destina-se à formação de professores para exercer funções de magistério na Educação Infantil e nos anos iniciais do Ensino Fundamental, nos cursos de Ensino Médio, na modalidade Normal, de Educação Profissional na área de serviços e apoio escolar e em outras áreas nas quais sejam previstos conhecimentos pedagógicos.

Parágrafo único.

II- planejamento, execução, coordenação, acompanhamento e a avaliação de projetos e experiências educativas não-escolares;

IV - trabalhar em espaços escolares e não-escolares, na promoção da aprendizagem de sujeitos em diferentes fases do 
desenvolvimento humano, em diversos níveis e modalidades do processo educativo. (BRASIL, 2006, p.2, grifo nosso).

Vários autores enfatizam que a Pedagogia não se limita a docência, visto que esta é uma das modalidades. Para Franco, Libâneo e Pimenta (2007, p. 89) o papel da Pedagogia "é promover mudanças qualitativas no desenvolvimento e na aprendizagem das pessoas, visando ajudá-las a se constituírem como sujeitos, a melhorar sua capacidade de ação e as competências para viver e agir na sociedade e na comunidade". Assim o pedagogo "é o profissional que cuida da formação humana em todos os lugares em que essa formação acontece de forma intencional e sistemática" (FRANCO; LIBÂNEO; PIMENTA, 2007, p.89). Para Ortega e Santiago (2009, p. 30) o pedagogo atua na formação humana em diversos espaços que se desenvolva 0 processo educativo, afinal até "pouco tempo, a escola era seu espaço restrito de trabalho e a sua formação bastava para atender a demanda pedagógica nela presente". Entretanto, segundo Leite e Lima (2010, p. 76) o "documento estabelece dezesseis atribuições para o pedagogo, que segundo Libâneo (2006), misturam objetivos, conteúdos e recomendações morais". A DCN deixa amplo o perfil docente, resultando numa totalidade vazia. Pimenta e Fusari
(2014, p. 38) numa pesquisa envolvendo os cursos de Pedagogia do Estado de São Paulo e constataram "agigantamento das matrizes curriculares e a diversidade de disciplinas oferecidas pelos cursos investigados, muitas sem aderência com a docência nos anos iniciais da educação básica, refletem o amplo, disperso e impreciso perfil do egresso definido pelas DCNs". Assim os cursos de Pedagogia, em sua maioria, não estão dando conta de formar nem o Pedagogo e nem mesmo o professor para os anos iniciais da educação básica.

\section{CONTEXTUALIZAÇÃO DA PEDAgogIA HOSPITALAR}

Segundo Dutra (2009) e Amorin (2011) a Pedagogia Hospitalar originou-se por volta de 1935 na França, quando Henri Sellier, prefeito da cidade de Suresnes, inaugurou a primeira classe hospitalar para atender crianças e adolescente em idade escolar que haviam sido vitimas de acidentes provocados pela Segunda Guerra Mundial que envolveu quase todas as nações no período de 1939 a 1945.

Amorin (2011) afirma que em 1939 surge na França o Centro Nacional de Estudos e de Formação para a Infância Inadaptadas (CNEFEI) objetivando a formação de professores para o exercício da Pedagogia Hospitalar em institutos especiais e em hospitais. Neste mesmo ano é criado o cargo 
de Professor Hospitalar pelo Ministério da Educação da França, mantendo estágios em regime de internato á médicos, professores, diretores de escolas e assistentes sociais. A criação de classes hospitalares é resultado do reconhecimento formal de que crianças hospitalizadas, independentes do período de permanência na instituição têm necessidades educativas e direito a cidadania, incluindo a escolarização.

No Brasil, a pedagogia hospitalar, surgiu no Rio de Janeiro em 1950, com a classe hospitalar, no Hospital Menino Jesus. E em São Paulo, a classe hospitalar foi implantada no mesmo ano no Hospital Santa Casa de Misericórdia, sendo que os primeiros atendimentos pedagógicos não dispunham de uma sala ou espaço especifico, e por isso os atendimentos eram realizados na própria enfermaria do hospital. Apenas pelo Estatuto da Criança e do Adolescente Hospitalizado (ECAH), mediante a Lei federal $\mathrm{n}$ - 8.242, 12/10/91a Pedagogia Hospitalar passa a ser reconhecida legalmente.

Ribeiro (2012, p. 7) esclarece que a Pedagogia hospitalar tem o papel de garantir a continuidade de aprendizado às crianças hospitalizadas, mesmo diante de situações adversas. Visto que a LDB/96 reconhece os "direitos de crianças e adolescentes de modo geral, bem como para aqueles que estão hospitalizados, pois ela propõe '[...] que todas as pessoas disponham dos meios necessários para evitar a suspensão do aprendizado'".

A Pedagogia hospitalar "busca oferecer assessoria e atendimento pedagógico humanístico tanto para o paciente quanto para o familiar, na busca de promover situações e atitudes educativas, a partir do efetivo envolvimento com o doente e com o ambiente" (ORTEGA; SANTIAGO, 2009, p.32). Na Pedagogia hospitalar temos várias modalidades, como a Hospitalização Escolarizada, Classe Hospitalar, a Pedagogia Domiciliar e o Atendimento a criança em albergue ou casa de apoio. Porém nessa pesquisa priorizamos a classe hospitalar que desenvolve a educação formal.

\section{PROFESSOR NA PEDAGOGIA HOSPITALAR:}

\section{PAPEL E DESAFIOS}

A atuação de docentes em hospitais é um tema polêmico, porém, acreditamos que o professor é um elemento fundamental na busca de qualidade do ensino, mas um profissional com formação qualificada e que compreenda criticamente seu papel e função no contexto educacional brasileiro, principalmente no espaço da Pedagogia Hospitalar.

A prática docente é fortemente marcada pelas relações afetivas, servindo de reforço para que a criança não desista da luta por sua saúde e se mantenha esperançosa em 
sua capacidade de esforço. O professor passa a ser um mediador de estímulos cauteloso, solícito e atento, reinventando formas para desafiar o enfermo quanto à continuidade dos trabalhos escolares, a vencer a doença e a engendrar projetos na vida emancipatória. (ORTIZ; FREITAS, 2005, p.67).

O pedagogo deve estar preparado para ocupar este lugar específico, conhecendo tal contexto e suas peculiaridades, interagindo com os profissionais que estão em contato direto com a criança em situação de internação, com os familiares, e conhecer a história de vida dos alunos procurando desenvolver um trabalho pedagógico eficiente ao auxílio do aluno neste momento delicado, possibilitando um processo de humanização no ato de educar. Outra metodologia utilizada é escuta pedagógica cujo objetivo é "acolher a ansiedade e as dúvidas da criança hospitalizada, criar situações coletivas de reflexão sobre elas, construindo novos conhecimentos que contribuam para uma nova compreensão de sua existência, possibilitando a melhora de seu quadro clínico" (FONTES, 2005, p. 135).

Dentre o trabalho com a Pedagogia hospitalar apresentamos a seguir alguns desafios:
Direito Negado: A Pedagogia hospitalar é um direito de todas as crianças hospitalizadas, mas isso não se efetiva em todos os hospitais, portanto é um direito negado, de certa forma a população. Há uma precariedade no número de classes hospitalares com atendimento pedagógico voltado ao paciente/aluno no Brasil.

\section{Desvalorização da Pedagogia}

Hospitalar: Consequentemente faltam profissionais preparados para atuar na área e a criança ou adolescente hospitalizada fica à mercê apenas dos cuidados médicos deixando de lado o seu processo de formação e apropriação de conhecimento.

\section{Relação com sofrimento e morte:} Para Zorzo (2004), a situação de morte de um paciente exige uma atitude de escuta, envolvimento, senso crítico e acolhimento, para a qual o professor muitas vezes não está formado, representando limitações para a perspectiva de humanização das práticas em saúde. Deparar-se com o sofrimento do outro pode ser uma experiência "humanizadora", mas esta situação de morte vivida pelo pedagogo hospitalar é vista como momento difícil.

Relação Pedagogo e família: A Pedagogia hospitalar coloca o professor e pedagogo como uma ponte entre os desejos, frustrações, ansiedades e medos do hospitalizado com o mundo externo e com suas famílias. As intervenções feitas pelo 
professor naturalmente restituem a autoestima dessas crianças fazendo crescer neles a vontade de viver. Distante da escola, essa criança não se distancia da família, pelo contrário; há uma tendência maior de aproximação entre os membros. A relação pedagogo e família é uma relação importantíssima nesse momento da vida do aluno enfermo.

Ausência de Estrutura Física: A estrutura física é um aspecto fundamental no trabalho do professor na classe hospitalar. Visto que é necessária uma sala de aula adaptada ao ambiente hospitalar para atender crianças e adolescentes em internação temporária ou permanente, garantindo seu vínculo com a escola e ajudando no seu ingresso e até retorno ao seu grupo escolar. Esse espaço precisa ser um local organizado e decorado com muita criatividade, com brinquedos diversos, para que a criança se sinta estimulada a ficar ali, até mesmo se esquecendo de que está em um hospital (CARDOSO; SILVA; SANTOS, 2012). Vale ressaltar que existe uma Lei Federal no 11.104, de 21/03/2005 que determina a obrigatoriedade de instalação de "Brinquedotecas" nos hospitais brasileiros. Esta lei é um avanço, mas não assegura um espaço lúdico nos hospitais, conforme constatamos.

Falta de profissionais qualificados: Em relação à formação, segundo Ribeiro
(2012), para atuar no campo da pedagogia hospitalar o pedagogo precisa ter formação específica com alguma especialização na área e, além disso, deve estar disposto a enfrentar esse desafio com muita criatividade e dedicação. Infelizmente os cursos de Pedagogia enfatizam a formação de professores em espaço escolar, não preparando os profissionais para atuarem espaços não escolares, como no caso os hospitais. E a formação dos profissionais da saúde, geralmente não enfatiza questões pedagógicas. Assim a formação de professores é um grande desafio para a Pedagogia Hospitalar.

\section{CONCLUSÃO}

Nos resultados da pesquisa constatamos a importância do professor na educação de crianças hospitalizadas e, também no atendimento aos seus familiares sobre o conhecimento do ambiente hospitalar, as novas condições de vida para o internado, as leis que asseguram os direitos a educação no hospital, e principalmente a continuidade no processo de ensino aprendizagem. Infelizmente os cursos de Pedagogia enfatizam a formação de professores em espaço escolar, o que torna a formação de professores um grande desafio. Cabe ao Pedagogo hospitalar garantir condições de acompanhamento, para o desenvolvimento cognitivo da criança, por 
meio de inclusão, socialização e mediação no processo de ensino aprendizagem com atividades lúdicas voltadas à infância. Nesse sentido, pesquisar a formação do professor para atuar nas classes hospitalares é de extrema importância no contexto atual.

\section{REFERÊNCIAS}

AMORIM, N.S. Histórico da pedagogia hospitalar: a pedagogia hospitalar enquanto prática inclusiva. Porto Velho, 2011. Disponível em: <http;//www.webartigos.com/artigos/históri co-da-pedagogia20hospitalar/

74994/\#ixzz2iLOVaeMw>. Acesso: 20 abr. 2014.

AQUINO, J G. Do cotidiano escolar: ensaios sobre ética e seus avessos. 2. ed. São Paulo: Summus, 2000.

BRASIL. Resolução do Conselho Nacional de Educação no 1, de 15 de maio de 2006. Institui as Diretrizes Curriculares Nacionais para o curso de Graduação em pedagogia, licenciatura. Diário Oficial da União, Brasília, 16 de maio de 2006, Seção 1, p. 11.

BRASIL. Lei $\mathrm{n}$ - 9.394, de 20 de dezembro de 1996. Estabelece as Diretrizes e Bases da Educação Nacional. Disponível em: http://www.presidencia.gov.br/legislacao/. Acesso em: 20 out. 2012.

CARDOSO, C.A.; SILVA, A F; SANTOS, M.A. Pedagogia hospitalar: a importância do pedagogo no processo de recuperação de crianças hospitalizadas. Cadernos da Pedagogia. São Carlos, Ano 5, v. 5, n. 10, p. 46-58, jan-jun 2012.

CONCEIÇÃO, J. M. (et al.). Pedagogia hospitalar: a educação no leito oferecida as crianças internadas no hospital infantil da zona leste de Manaus. In: CONGRESSO
BRASILEIRO DE EDUCAÇÃO ESPECIAL, 3.. Anais... São Carlos, 2008.

DUTRA, V A. História da pedagogia hospitalar no brasil. 2009. Trabalho (Conclusão de Curso) - Universidade Estadual de Londrina, Londrina - PR.

FONTES, R S. A escuta pedagógica à criança hospitalizada: discutindo o papel da educação no hospital. Revista Brasileira de Educação, v. 29, n. 2, p. 119-139, 2005. http://dx.doi.org/10.1590/S1413-

24782005000200010

FRANCO, M. A.; LIBÂNEO, J. C.; PIMENTA, S. G. Elementos para reformulação de diretrizes curriculares para cursos de Pedagogia. Cadernos de Pesquisa [online], v. 37, n.130, p. 63-97, jan/abr. 2007.

LIBÂNEO, J. C.; OLIVEIRA, J. F; TOSCHI, M. S. Educação escolar: políticas, estrutura e organização. São Paulo: Cortez, 2003.

LIBÂNEO, J. C. Diretrizes curriculares da pedagogia: imprecisões teóricas e concepção estreita da formação profi ssional de educadores. Educação \& Sociedade, Campinas, n. 96, v. 27, out. 2006.

PIMENTA, S. G.; FUSARI, J. C. (et al.). A formação de professores para a Educação Infantil e para os anos iniciais do Ensino Fundamental: análise do currículo dos cursos de Pedagogia de instituições públicas e privadas do Estado de São Paulo. Relatório Técnico de Pesquisa. fev. 2014. 47p.

RIBEIRO, K. R. Pedagogia hospitalar: a escolarização do aluno no atendimento pedagógico domiciliar. Trabalho (Conclusão de Curso) - Universidade Estadual de Maringá, Maringá - PR. 2012. Disponível em: <http://www.dfe.uem.br/TCC/Trabalhos_201 2/KARINA_RIBEIRO.pdf> Acesso em: 10 set. 2013. 
ORTEGA, L; SANTIAGO, N. A atuação do pedagogo: que profissional é esse? Pedagogia em ação, v.1, n.2, p. 29-35, ago/nov. 2009.

ORTIZ, L. C. M; FREITAS, S. N. Classe hospitalar: caminhos pedagógicos entre saúde e educação. Santa Maria: Editora UFSM, 2005. disponível em: <http://www.psicopedagogia.com.br/artigos /artigo.asp?entrID=1039>. Acesso em: 10 set. 2013.

ZORZO, J. C. C. O processo de morte e morrer da criança/adolescente: vivências dos profissionais de enfermagem. 2004. Dissertação (Mestrado) - Escola de Enfermagem de Ribeirão Preto, Universidade de São Paulo, Ribeirão Preto - SP.

Recebido para publicação em 11/08/2014

Revisado em 25/08/2014

Aceito em 01/09/2014 